\title{
A ORGANIZAÇÃO POLIITICA NO SÉCULO XIV SEGUNDO O “TRATADO SOBRE A MOEDA" DE NICOLE ORESME
}

Sueli Sampaio Damin Custódio* smdamin@gmail.com

RESUMO Este artigo mostra como Oresme orienta o leitor do "Tratado" a pensar a organização da vida política no processo histórico do século XIV a partir do estudo sobre a alteração da moeda.

Palavras-chave "Tratado sobre a moeda", autoridade política, organização política no século XIV.

ABSTRACT This paper shows how Oresme guides the reader of his "Treatise" to a thought in order to connect the organization of political life in the historical process of the $14^{\text {th }}$ Century based on the study on the change in money.

Keywords "Treatise on Money", political authority, political organization in $14^{\text {th }}$ Century. 
Nicole Oresme expôs no "Tratado sobre a moeda" um modo peculiar de tratar o problema das escolhas políticas na França do século XIV a partir do seu estudo sobre a moeda. Em que pese o autor ter dedicado boa parte da obra descrevendo a especificação das propriedades da moeda, a sua criação e o seu processo de cunhagem, seu "Tratado" expõe princípios e fins próprios da Política, e especialmente, aborda ações que orientam a constituição de um bom principado.

De fato, a moeda e o processo de sua circulação são investigados pelo autor com o intuito de entender o tipo de autoridade que deve existir nesse sistema de trocas de riquezas. Para isso, o autor parte do argumento de que o uso da moeda deve atender ao interesse público geral, ${ }^{2}$ sustentando que a moeda foi instituída como um instrumento de equalização das sociedades humanas por permitir que pessoas com ocupações e status social distintos pudessem trocar bens de valor desigual e, ainda assim, pudessem obter, com a troca, uma equalização de seus interesses. Assim, o "Tratado", mais do que um debate sobre os problemas econômicos do século XIV, será apresentado como um estudo sobre as práticas políticas que se constituem a partir dos diferentes usos atribuídos à moeda.

O propósito deste artigo é investigar como a moeda, ao ser elevada a meio de equalização e garantia de medida, torna-se elemento fundante de uma nova concepção de autoridade, calcada na distribuição da justiça das trocas. Tal estudo se justifica porque o "Tratado" evidencia a alteração da organização social, qualitativa e rígida, na qual as relações entre os homens constituemse por natureza para uma organização social quantitativa e móvel, na qual as relações entre os homens se alteram segundo a estimativa de valores atribuídos às coisas e aos homens envolvidos. Tais valores, por seu turno, são passíveis de alteração segundo algumas condições.

Com o intuito de desenvolver o meu objetivo, baseio minha análise na apresentação argumentativa do autor de três pontos: 1) a natureza da moeda,

1 Cito o "Tratado" a partir das seguintes edições: N. Oresme, 1864. Réimpression Genève: Slatkine Reprints, 1976, doravante citado como "Des monnoies, p." e como apoio de tradução foi usada a edição N. Oresme, 1956, doravante citado como "De moneta, p.". O texto do Tratado dispõe de versões em latim e francês. A primeira versão de que se tem notícia é em latim e tem 23 capítulos "Tractatus de origine, natura, jure et mutationibus monetarum". Segundo Wolowski, essa versão recebeu o acréscimo de mais três capítulos depois do episódio do pagamento de resgate de João II (1357-8) e foi traduzido para o francês em 1367, a pedido de Carlos V, com os 26 capítulos.

2 Oresme analisa o uso da moeda seguindo o argumento aristotélico. Ao expor a finalidade da moeda, cita expressamente o Livro V, da "Ética": "Et ainsi, sans autre approbacion, clèrement peult apparoir que la monnoie est moult utile et nécessaire pour le bien de la communaulté publicque, voire et encores très nécessaire, comme appreuve Aristote, en son cinquiesme livre des Ethicques [...]" (N. Oresme, "Des monnoies», pp. IX-X). 
ou seja, a finalidade para a qual a moeda foi criada $;^{3} 2$ ) os debates sobre a quem pertence a moeda e a quem cabe fabricá-la e alterá-la; ${ }^{4} 3$ ) os usos justos da moeda, ou seja, os usos que atendem a finalidade para a qual a moeda foi criada. $^{5}$

Minha hipótese de leitura busca apontar que os argumentos apresentados por Oresme associam o bom uso da moeda no reino à manutenção do poder do príncipe $^{6}$ e seguem a tradição aristotélica por duas razões. A primeira porque o autor utiliza os argumentos presentes nos textos da "Política" e da "Ética" de Aristóteles com o intuito de expor a origem da criação da moeda e de sua finalidade em atender ao interesse público geral, para depois esclarecer o papel do príncipe e da comunidade no processo de fabricação e de circulação da moeda. A segunda razão decorre do argumento de que o príncipe deve agir e se portar em vista do que é nobre, e por consequência, deve ter uma conduta honrada em relação à moeda em seu reino.

A conduta ética esperada do príncipe está presente desde o início do "Tratado" com a exposição dos perigos e danos possíveis em vista da não observância do uso justo da moeda no reino. ${ }^{7}$ A própria questão introduzida pelo Prólogo é bastante reveladora, uma vez que o autor inicia o "Tratado" perguntando se o "príncipe pode alterar ou dispor livremente das moedas correntes em seu reino" (N. Oresme, "Des monnoies", prólogo, p. II), por meio da exposição de teses contrárias.

$\mathrm{O}$ debate se inicia com a exposição de um conjunto de argumentos referentes aos usos injustos da moeda e à necessidade de se discutir a real natureza da mesma, ${ }^{8}$ e por consequência, discutir qual deve ser a conduta do príncipe no reino. Para o autor, uma vez que se tenha clareza da natureza da moeda, a alteração da mesma não poderá ser tolerada, sobretudo porque,

3 Oresme expõe a natureza da moeda a partir da análise de sua função como riqueza artificial, esclarecendo que a mesma não supera de imediato a necessidade humana: "[...] car toutes pecunes sont dictes artificielles richesses et non autrement, actendu qu'il peut avenir que aucun habundant en icelles, encores pourroit mourir de fain de lez elles [...]" (N. Oresme, "Des monnoies", p. IX).

4 Esses debates estão presentes de modo mais sistematizados nos Capítulos V, VI, VIII, IX, X e XXIV.

5 Essa discussão está presente em todo o "Tratado", mas o autor retoma o argumento, principalmente, no capítulo XXIV.

6 Oresme deixa essa associação mais clara no capítulo XXV: "Le vingt cinquiesme, comment le tirant prince ne peult longuement durer" (N. Oresme, "Des monnoies", p. VI).

7 "[...] pelo prólogo e os títulos dos capítulos referidos, desvendam-se, ainda que em parte, os perigos, danos e inconvenientes que podem acontecer e que já despontam no reino ou no país onde se toleram tais abusos com a moeda e os metais nobres dos quais ela é e deve ser feita" (N. Oresme, "Des monnoies", prólogo, p. VII).

8 Cf. N. Oresme, «Des monnoies», prólogo, p. II. 
"quando a verdade se torna manifesta, toda a opinião deve ceder e dar lugar à verdade" (N. Oresme, "Des monnoies", prólogo, pp. I-II). ${ }^{9}$

Com o intuito de demonstrar a influência aristotélica no "Tratado", esse artigo usará o "Des monnoies", como fonte primária, além dos "Comentários à Política" 10 e dos "Comentários à Ética" $" 11$ como fontes de apoio. No "Tratado", há referências diretas aos textos aristotélicos, ${ }^{12}$ inclusive, no Prólogo, o autor esclarece que: "é em razão de tal controvérsia e debate que me proponho expor, neste pequeno tratado, o que, seguindo principalmente a filosofia e as razões de Aristóteles, na minha opinião deve ser dito" (N. Oresme, "Des monnoies", prólogo, p. II). ${ }^{13}$

\section{A origem da moeda e os seus atributos}

No Capítulo I do "Tratado", o autor expõe que a moeda foi criada como instrumento equivalente para permutar riquezas naturais. ${ }^{14}$ Como riqueza artificial instituída, visa satisfazer as necessidades humanas, devendo ser útil e oportuna para o bem da comunidade e para o interesse público. ${ }^{15}$ Até porque, segundo o autor, "... com a moeda não se supera de imediato a indigência da vida humana" (N. Oresme, "Des monnoies", p. IX). ${ }^{16}$ Depreende-se disso que a moeda foi criada para atender um fim específico, o de servir de instrumento de equivalência no qual se estabeleça uma relação habitual entre uma coisa e outra, em que valor e preço devem ser observados.

9 "Veritate manifestata, cedat oppinio veritati". Ao desenvolver o argumento, Oresme informa a razão para a qual o debate se apresenta: “... afastadas quaisquer dúvidas, os sábios e os homens avisados possam convir todos numa verdadeira e profícua opinião e, de acordo com ela, encontrar o que para os príncipes, para os súditos, ou antes, para o interesse público geral possa ser proveitoso" (N. Oresme, "Des monnoies", prólogo, p. I-II).

10 Cito a versão francesa N. Oresme, 1960, doravante citada como "Comentários à Política", seguida de livro, capítulo e paginação. Para as traduções e cotejamento, consultei Aristóteles, "Politics", 1991, pp. 19862129.

11 Cito a versão francesa N. Oresme, Le Livre de Ethiques d'Aristote, 1940, doravante citada como "Comentários à Ética", seguida de livro, capítulo e paginação. Para as traduções, também consultei as versões C. Natali, 2009; Aristóteles, 1915; M. Zingano, 2008.

12 No "Des monnoies", Oresme cita vinte e duas vezes o Aristóteles, sendo dezenove vezes a Política, Livros I, II, III, V e VII, e três vezes a "Ética", Livros I e V. Cabe registrar que o autor tinha familiaridade com os textos, inclusive, traduziu para o francês a "Ética", em 1370, e os "Comentários à Política", em 1372.

13 "Pour laquelle controversie et débat, j'entens em ce, petit present Traictie, quelle chose, selon philosophie et principalement selon les raisons d'Aristote, il me semble estre à dire [...]."

$14 \mathrm{Cf}$. "Et pour ce doncques que monnoie est l'instrument pour permuer les Richesses naturelles [...]"( $\mathrm{N}$. Oresme, «Des monnoies», p. XI).

15 Cf. N. Oresme, «Des monnoies», p. IX.

16 Oresme («Des monnoies», p. IX) cita o exemplo de Midas para enfatizar o argumento: "[...] si comme exemplifie et mect par histoire le philosophe Aristote d'un Roy convoiteux que Ovide, en son livre de Métamorphose, nomme Midas [...]." 
Por ser um instrumento artificial de medida e valor que visa satisfazer as necessidades humanas, a moeda é determinada por uma série de ordenações e fundamentos necessários para alcançar o fim da vida política no principado, dentre eles, o autor expõe que a "moeda é coisa que pertence à comunidade e aos particulares" (N. Oresme, "Des monnoies", p. XXXII) $)^{17}$ e destaca o papel do príncipe no processo de fabrico, cunhagem e supervisão da moeda e o grau de aceitação da moeda do reino pela comunidade, mercadores e particulares. ${ }^{18}$

Para Oresme, "a moeda deve ser justa e verdadeira em substância e peso" (N. Oresme, "Des monnoies", p. XLIII), sobretudo porque a mesma foi instituída para o bem da comunidade. Por ser uma riqueza artificial criada pelo homem, a moeda por si mesma nada significa senão a partir do uso que é dado pelo próprio homem. Nessa medida, a concepção quantitativa de mundo encontrada na análise do autor sobre o papel da moeda traz elementos elucidativos sobre a forma com a qual o mesmo percebia a vida cotidiana das cidades medievais, em especial a autoridade do príncipe sobre a moeda. Isso se evidencia quando o autor defende que o valor da moeda não deve refletir as necessidades da corte ou da burocracia do reino, mas deve necessariamente atender ao interesse público geral e respeitar a ordem natural e racional para qual foi criada; evitando, de todo modo, a fraude, ${ }^{19}$ sobretudo porque a fraude desonra o príncipe e o próprio reino.

Compreende-se por moeda justa aquela que atende a certos atributos, prescrições e leis fundamentais. Os atributos da moeda apresentados por Oresme são de três ordens: 1) da função - a moeda deve ser útil e servir à comunidade como instrumento de equivalência para permutar as riquezas naturais entre homens; 2) da qualidade - a moeda deve ser feita de matéria preciosa e pouco volumosa para facilitar o seu manejo no reino e nas relações de trocas. Para o autor, a moeda boa e verdadeira em sua substância estimula os mercadores a trazer suas riquezas e boas mercadorias para o reino; e 3) da extensão - a moeda deve ser facilmente identificada e reconhecida pela comunidade, mercadores e particulares no reino. Para atender aos atributos expostos acima, Oresme inicia, na passagem a seguir, a apresentação das prescrições a serem observadas:

17 "[...] de rechief, du premier et sixiesme chappitres, appert assez que pecune et monnoie est chose appartenant à la communaulté et aux personnes singulières [...]."

18 Sobre o interesse filosófico gerado pelos problemas econômicos do século XIV cf., Courtenay, 1972.

19 Oresme cita Cassiodoro para desenvolver esse argumento: “... Com efeito, violar certos segredos da natureza, querer confundir as coisas certas, não é outra coisa senão mutilar cruelmente e vergonhosamente a própria verdade. O peso e a medida, acima de tudo se conservam como prova da verdade, pois todas as coisas ficarão conturbadas se a sua integridade se misturar com a fraude..." (N. Oresme, "Des monnoies", p. XLIX). 
É sábio e prudente que parte da moeda seja feita de certa matéria e com peso determinado, e que nela seja impressa uma figura conhecida por todos, significando a qualidade da matéria e o verdadeiro peso da moeda, de modo a se evitar a suspeita e a se conhecer com facilidade o valor. (N. Oresme, De moneta, p. 8) ${ }^{20}$

Oresme expõe que as prescrições sobre a moeda devem ser estabelecidas em vista do cumprimento de seus atributos, iniciando o seu debate pela discussão de quem cabe fabricar a moeda.

\section{A quem compete fabricar a moeda}

Para Oresme, o príncipe é mais nobre quanto mais zelar pelos interesses de seus súditos. No caso da moeda, a nobreza do príncipe está diretamente associada à sua capacidade de colocar ordem na mesma, ou seja, é princípiodever do príncipe observar em suas ações a finalidade para qual a moeda foi criada. Nesse sentido, como maior autoridade pública da região, cabe ao príncipe a honra de fabricar a moeda,${ }^{21}$ de modo que, sob seu comando, evitem-se a falsificação, a reprodução indevida e a alteração da mesma. $\mathrm{O}$ autor defende que o príncipe deve ter a virtude adequada à atribuição que lhe foi conferida pela comunidade e não permitir ou tolerar o mau uso da moeda em seu reino.

Para Oresme, o príncipe não tem o poder de alterar a moeda e qualquer apropriação que faça é injusta e iníqua. De novo recorre ao Filósofo para expor o argumento: “... qualquer coisa, diz Aristóteles, que o príncipe faça em prejuízo ou dano à comunidade é injustiça e fato tirânico, não digno de um rei” (N. Oresme, "Des monnoies", p. XLVI). Percebe-se aqui que o autor continua seguindo o pensamento aristotélico quando defende que o príncipe precisa ser virtuoso, uma vez que serve de espelho para os seus súditos, que o imitam. Nessa medida, seus vícios corrompem os governados e destroem o principado. Por conta disso, o príncipe deve deliberar sobre as coisas que existem em vista dos fins a serem alcançados pelo uso justo da moeda.

Essa passagem do "Tratado" lembra igualmente o argumento de Aristóteles (EN, IX.8, 1169 a2) segundo o qual "somos propriamente o que pensamos", 22 isto é, quando o sujeito pensa, o exercício é dele, e isto implica

20 " [...] ideo per sapientes illius temporis prudenter provisum est, quod porciones monete fierent de certa materia et determinati ponderis, quodque in eis imprimeretur figura que cunctis notoria significaret qualitatem materie nummismatis et ponderis veritatem, ut amota suspicione posset valor monete sine labore cognosci".

21 Cf. N. Oresme, «Des monnoies», p. XXI.

22 Ver, por exemplo, o argumento em EN, IX. 8, 1169 a2. 
dizer que o princípio da ação encontra-se no próprio sujeito e não fora dele. Portanto, as ações humanas, quando não constrangidas nem ignorantes, são escolhas voluntárias. Da mesma forma que o bem é alcançável pelo agir que dura a vida toda, sobretudo porque decorre da atualização das potências da alma humana em sua excelência, a racionalidade. Assim, as ações humanas, por envolver deliberação e escolha, referem-se ao tempo futuro como juízos possíveis. Segundo Aristóteles, ${ }^{23}$ deliberamos sobre o possível e o futuro e sobre as coisas que dependem de nós e que podemos realizar pela seguinte tríade: 1) existe uma vontade deliberativa para escolher a ação; 2) essa escolha está direcionada ao tempo futuro e, portanto, no campo do meramente possível e não do necessário; 3) o homem, por natureza, é dotado ao mesmo tempo de vontade racional e de desejo (órexis).

As ações do príncipe são apresentadas por Oresme da mesma forma, ou seja, o príncipe dispõe de vontade deliberativa para escolher manter o bom uso da moeda em seu reino; as escolhas do príncipe direcionam a futura política monetária do reino; o príncipe, por ser homem, é dotado do desejo de se enriquecer por meio da moeda, mas também da vontade racional de ser um bom príncipe, ou seja, um nobre. A partir dos fundamentos próprios da Ética, Oresme expõe as prescrições com as quais as ações no principado devem se constituir. Nessa medida, as prescrições são apresentadas para balizar a conduta humana, seja ela do príncipe, da comunidade ou dos particulares. De fato, a moeda é percebida como um instrumento pelo qual a justiça das trocas pode ser realizada.

Partindo do argumento aristotélico, o autor defende a prescrição de que a moeda não deve ser alterada sem necessidade evidente e expõe que o príncipe detentor do poder aparente sobre a moeda deve evitar o excesso ou a carência, buscando o termo médio em seus atos de modo a propiciar a regulação e o uso natural e justo da moeda em seu reino. ${ }^{24}$

Para Oresme ("Des monnoies", p. XXVI), "o curso e o preço das moedas devem ser considerados no reino como uma lei e prescrição firme..." para todos, ou seja, para príncipe, comunidade, mercadores e particulares. Percebe-se aqui que essa prescrição está diretamente relacionada à função da moeda, uma vez que a utilidade da mesma permanecerá enquanto ela tiver boa receptividade no reino. Com isso, Oresme recorre novamente ao argumento aristotélico e

23 Cf. M. Zingano, 2008.

24 "[...] Par ceste raison preuve Aristote, ou premier des Politiques, que usure est chose contre nature, car le naturel usaige de la monnoie est qu'elle soit instru ment à permuer et achecter les Richesses naturelles, comme souvent est dit: qui doncques use d'elle par autre manière, il se abbuse et fait contre l'institucion naturelle de la monnoie [...]” (N. Oresme, «Des monnoies», pp. XLVIII-XLIX). 
defende que "a coisa que mais firmemente deve permanecer igual é a moeda" (N. Oresme, "Des monnoies", p. XXVI). ${ }^{25}$ As justificativas apresentadas por ele se assentam na relação esperada do poder existente entre governante e governado, ou melhor, entre o príncipe e seus súditos. O autor desenvolve o seu argumento expondo o tipo de governo esperado para o controle sobre a moeda e, na hipótese da degeneração desse governo, aponta a possibilidade de desobediência ou sedição por parte dos súditos, sobretudo porque as alterações na moeda seriam identificadas como intoleráveis e injustas.

\section{O uso justo da moeda}

Seguindo Aristóteles, tal qual na "Política" III.6, Oresme defende que o uso justo da moeda está restrito a cidades, ou melhor, a principados com bons governantes, sobretudo porque a ação politicamente justa é possível apenas entre pessoas livres e iguais. ${ }^{26}$ Dessa forma, arranjos políticos incorretos, como, por exemplo, a tirania, não satisfazem as condições de liberdade ${ }^{27}$. De fato, a moeda justa é tratada pelo autor em vista da ação e da conduta nobre esperada do príncipe. Considera-se nobre o príncipe que exercer o poder conforme as leis justas e os bons costumes ${ }^{28}$, pois, segundo Oresme, é "a quem é devido o tributo, pois ele é devido àquele que milita e combate pela coisa pública, e que para a defesa do reino e a utilidade pública, pode fabricar a moeda" (N. Oresme, "Des monnoies", p. XXI).

Assim, no "Tratado", o agir esperado do príncipe passa a ser tratado segundo a tradição aristotélica ${ }^{29}$ e, mais especificamente, a partir da teoria dos meios. O texto versa sobre o fim a ser alcançado pelo uso da moeda, a essência dos agentes e das ações e os meios para realizá-lo. Nesse cenário aristotélico do século XIV, o príncipe temperante é aquele que tem os fins moralmente bons, com a ressalva interpretativa que, segundo a teoria dos meios, ter bons fins não é condição necessária para a imputação moral, já que, para isso, há

25 "[...] A ce propos, dit Aristote, en son cinquiesme livre des Ethiques, parlant des monnoies: Certainement la chose qui plus fermement doit demourer en estre est la monnoie".

26 Cf. N. Oresme, «Des monnoies», p. LXXIII.

27 "[...] uma comunidade de cidadãos, que é naturalmente livre e tende à liberdade, jamais conscientemente, se submeteria à escravidão, ou se curvaria sob o jugo do poder tirânico" (N. Oresme, "Des monnoies", pp. LXXII-LXXIII).

28 "[...] Et combien que ceste chose semble, de prime face, illicite et mauvaise, toutesfoiz ceste monopole de monnoie est encore plus vraye tyrannie, actendu qu'elle est non voluntaire et non nécessaire à la comunaulté, mais précisement dommaigeable [...]" (N. Oresme, «Des monnoies», p. LXXIII).

29 "[...] Quelconque chose, dit Aristote, que le Prince face ou préjudice ou dommaige de la communaulté est injustice et fait tyrannique et non pas réal, et s'ildisoit, comme soullent les Tyrans mentir, qu'il convertit iceluy gaing en l'utilité publique, il n'est à croire à luy ne à son seul dit [...]" (N. Oresme, "Des monnoies", p. XLVI). 
que se deliberar sobre os meios empregados para atingir tal finalidade. $\mathrm{O}$ autor segue esse pensamento aristotélico quando expõe os limites à autoridade do príncipe, argumentando "[...] que não é lícito fazer o mal para que dele advenha o bem" (N. Oresme, "Des monnoies", p. XLVI).

Observe-se que a moeda, por ser tratada como um "instrumento de equivalência para trocas de riquezas natural", deve servir à comunidade e ao fim de um bem viver. Por conta disso, deve atender a algumas condições necessárias e suficientes. Nesse sentido, o sistema de troca ao qual o autor se refere deve servir ao bem comum e não somente aos interesses do príncipe, de seu reino ou de particulares.

De fato, o atributo "justo" da moeda é associado ao tipo de governo constituído no reino. Para Oresme, o estudo dessa constituição é visto como necessário, uma vez que dá a estrutura e ordem ao principado, e consequentemente, estabelece a ordem para a moeda, propiciando o cumprimento de sua função. Percebe-se mais uma vez que Oresme recorre a Aristóteles, mais especificamente à "Política", para expor o seu argumento, em especial, o poder soberano do reino e sua degeneração em tirania. Assim, questões como "quem governa" e "como governa" constituem a base segundo a qual Oresme distingue o bom principado, ou seja, a boa forma de governo. A tipologia apresentada pelo autor segue o pensamento aristotélico inclusive no critério hierárquico usado para o estudo das diferentes formas de governo e suas degenerações quando associa a prática de alteração da moeda à tirania. ${ }^{30}$

Oresme expõe a tirania como a pior forma de degeneração de governo ${ }^{31}$ uma vez que não observa o interesse comum. Desse modo, o critério aristotélico "interesse comum versus interesse pessoal" serve para definir o tipo de governo e passa a ser incorporado ao argumento do autor com o intuito de entender as práticas políticas exercidas sobre a moeda pelo príncipe. Para Oresme, a boa forma de governo é aquela em que o príncipe visa o interesse comum tal qual concebia Aristóteles, sobretudo porque, na concepção do autor, o principado se constitui em uma comunidade política não apenas porque os indivíduos querem ter uma vida em comum, mas porque visam um bem viver. Assim, quando o governante se aproveita do poder conferido pela comunidade para perseguir interesses particulares, o principado assume uma forma política

30 "Considero que a causa primeira e última pela qual o príncipe quer ter o poder de alterar a moeda não é senão que, com isso, ele vise obter vantagens em proveito próprio [...]" (N. Oresme, "Des monnoies", p. XLVIII).

31 Nesse sentido, continua seguindo a tipologia de Aristóteles (EN, L 1160a): "Delas a melhor é o reino, e a pior é a tirania". 
degenerada e corrompida, uma vez que essa comunidade se realiza menos bem, ou seja, afasta-se do fim do bem viver.

Por isso mesmo, o argumento de Oresme em manter a moeda firme e não passível de alterações pode ser interpretado em seu aspecto prescritivo, uma vez que não se limita a descrever os diferentes usos atribuídos à moeda; ao contrário, o autor inicia a sua exposição no "Tratado" indicando o principado como a melhor forma de governo para supervisionar o uso da moeda, e desse modo, institui uma ordem de preferência entre os tipos de governo. Sustento, com isso, o propósito do autor em orientar o leitor do "Tratado" a pensar a organização da vida política no processo histórico do século XIV a partir do estudo da política monetária e dos fenômenos econômicos.

O sistema monetário constituído à época baseava-se em alguns aspectos, entre eles no hábito social de usar a moeda do reino para negociações e trocas de bens e serviços por outros. Embora a moeda não tivesse um valor intrínseco, a pessoa que a recebia estava confiante de que, no futuro, uma terceira pessoa a receberia em troca de algo. Desse modo, o hábito se constituía em vista da confiança da moeda usada no reino e por ela representar um direito a serviços e bens no futuro que as pessoas precisassem ou desejassem. Acresce-se a isso o fato de a moeda "confiável e boa" propiciar maior circulação de riquezas no reino, sobretudo porque, com maior circulação de mercadorias, gêneros alimentícios e serviços, propiciava-se um bem viver a todos da comunidade.

Oresme, ao estudar o sistema monetário da época, destacou duas funções específicas importantes da moeda: 1) a de ser um meio efetivo de trocas de bens e serviços; e 2) a de servir como reserva de valor ou riqueza para particulares ou para o reino. No primeiro caso, a transferência da moeda de uma pessoa para outra permitia que as negociações ocorressem. Nesse particular, a moeda era necessária e suficiente para que as trocas acontecessem, especialmente porque era o instrumento ou meio escolhido comumente aceito.

O autor expõe, desse modo, que o uso da moeda decorre de uma convenção, e por consequência, a permanência da mesma está associada ao cumprimento de certos requisitos de admissibilidade para o seu uso, por exemplo, ser durável, facilmente identificável, ter alto grau de aceitação por quem a usa e respeitar os costumes comerciais entre os povos a respeito da proporção estabelecida entre as diferentes moedas existentes e aceitas no reino. Ao fazer isso, Oresme demonstra que as alterações na moeda não atendem a esses requisitos, uma vez que ocasionam insegurança para quem a usa e, portanto, tais alterações não devem ser aceitas pela comunidade e pelos particulares.

A segunda função da moeda, no entanto, ganha maior atenção no “Tratado". Isso pode ser justificado em razão de dois aspectos. Primeiro porque 
a moeda pode ser um meio de manter a riqueza, ou seja, como referência de reservas de valor que permitem a transferência do poder de compra ou troca do presente para o futuro. A preocupação de Oresme não é sem propósito, especialmente se considerarmos, como Le Goff (1980), que a cidade medieval ganha sentido somente quando vista como um sistema de aquisição e distribuição de mercadorias em proporções tão elevadas que demandava a quantificação e a medição de todas as coisas (1972, pp. 71-95). Outro aspecto a ser destacado decorre da plasticidade da moeda como meio de quantificação e representação de valor, possibilitando que se meça e compare não apenas preço de mercadorias, mas também o status social, o poder, a propriedade de terras, o trabalho e qualquer qualidade que se atribua ao homem que vive em comunidade.

Segundo a concepção aristotélica, o homem, por ser um animal político por natureza, deve buscar a vida em comunidade e, nessa medida, foi dada ao homem a linguagem não apenas para comunicar os seus sentimentos, como dor ou prazer, mas para exprimir valores na própria comunidade, como a percepção do bom e do mau ou do justo e injusto. Desse modo, a polis, ou no caso de Oresme, o principado, é constituído em vista de um certo bem. De fato, o principado como comunidade política se distingue pelo tipo de poder ou autoridade exercida pelo príncipe. No caso do "Tratado", o autor defende que o poder de um bom principado é público, uma vez que deve ser definido por leis e exercido entre os iguais. Contudo, como tudo que existe no mundo sublunar, a forma de governo da realeza pode se submeter ao perecimento e à corrupção e se tornar uma tirania.

Por conta disso, para Oresme, não se deve encorajar o comportamento ganancioso e corrupto do príncipe. $\mathrm{O}$ autor deixa claro esse ponto de vista na denúncia que faz, em seu sermão de natal ao Papa Urbano $\mathrm{V}$, dos excessos e gastos exorbitantes da corte de Avignon ${ }^{32}$ ou em sua preocupação, expressa nas quodlibetais, de que o uso cada vez mais extenso da moeda, abrangendo todos os aspectos das relações entre os homens na sociedade, resultasse na compreensão equivocada de que o meio e a medida, isto é, a moeda, é o próprio fim que se busca. Assim, diz Oresme, já há homens que conhecem mais sobre a moeda do que sobre aquilo que deveria ser medido e valorado por ela:

Tenho visto muitos que sabem de pronto como me dizer sobre um florim, "este é falso, aquele é bom", ainda que em peso, figura e cor sejam tão similares que não percebo qualquer diferença, mesmo que tenha a intenção de considerar profundamente, e 
mesmo aquele é ignorante do modo pelo qual conhece, exceto que parece ser o caso para ele. (N. Oresme, 1985, pp. 308-310) 33 $^{33}$

Percebe-se, nessa passagem, que a moeda deixa de ser considerada meio para ser considerada fim. Conforme já exposto, o valor da moeda não deve refletir as necessidades da corte ou do reino, nem de um particular, pois nesses casos a moeda seria percebida a partir de sua destinação privada, não observando, desse modo, a finalidade pública para a qual foi criada. Para concluir, defendo que as consequências políticas e sociais de tal inobservância já são apresentadas no "Tratado sobre a moeda" e não se pode negar que o autor apresenta um aspecto relevante da autoridade político-monetária nas sociedades europeias do século XIV, em que a moeda e o seu curso ocupam papel preponderante na arte de governar.

\section{Referências}

ARISTOTLE. "Nicomachean Ethics". The works of Aristotle translated into English by Ross. Oxford: Oxford University Press, 1915. Vol. 9.

ARISTOTLE. “Aristotle's Nicomachean Ethic". Ed Natali, C., Book VII. Oxford: Oxford University Press, 2009.

BABBITT, S. M (ed.). "Oresme's Livre de Politiques and the France of Charles V". Transactions of the American Philsophical Society, New Series. Vol. 75, Nr. 1, 1985. BERLANGA, J. L. V. "Jurisdicción y política en el siglo XV: Tiranía y reforma del reino". Res Publica, Vol. 18, pp. 225-245, 2007.

BERTELLONI, F. "Algunas reinterpretaciones de la causalidad final aristotélica en la teoría política medieval". Cadernos de História e Filosofia da Ciência, Série 3, Vol. 15, Nr. 2, Jul.-Dez. 2005.

BRIDREY, E. "La théorie de la monnaie au XIV siècle". Tese de doutoramento em Direito e Economia. Caen, 1906.

BURIDAN.) "Quaestiones in decem libros ethicorum Aristotelis ad Nicomachum". Oxford, 1637.

CIPOLLA, C. (ed.). "The Fontana Economic History of Europe: The Middle Ages". London, 1972.

COURTENAY, W. "The King and the Leaden Coin: The Economic Background of 'Sine qua non' Causality”. In: Traditio, 1972. Vol. 28, pp. 185-210.

33 'Vidi autem multos qui statim de uno floreno sciverunt michi dicere 'Iste est falsus, ille est bonus', et tamen in pondere et figura et colore erant ita similes quod nullam differentiam scivi percipere, quamvis ex intentione propria fortiter considerarem, ymo ipsemet nesciebat michi dicere quomodo cognos; ceret nisi quia sic apparebat ei et cetera" (N. Oresme, 1985, pp. 308-310). 
CUSTÓDIO, M. A. "Classificação das ciências que tratam da matéria em Tomás de Aquino". Cadernos de História e Filosofia da Ciência, Vol. 17, pp. 149-170, 2007.

DE ROOVER. "San Bernardino of Siena and Sant'Antonino of Florence: The Two Great Economic Thinkers of the Middle Ages". Boston: Harvard, 1967.

GILLARD. "Nicole Oresme, sujet théorique, objet historique". In: Quillett, 1990.

KAYLE. "Economy and Nature in the Fourteenth Century; Money, Market Exchange, and the Emergence of Scientific Thought". Cambridge: University Press, 2004.

LANGHOLM. "Price and Value in the Aristotelian Tradition". Bergen: Universitetsforlaget, 1979.

LANGHOLM. "Scholastic economics”. In: T. S. Lowry, 1987, pp. 117-134.

LE GOFF, J. "Time, Work, and Culture in the Middle Ages". Chicago: University of Chicago Press, 1980.

LE GOFF, J. “The Town as an Agent of Civilization 1200-1500”. In: C. Cipolla (ed.), 1972.

LOWRY, S. T (Ed.). "Pre-Classical Economic Thought". Boston: Kluwer, 1987.

MEUNIER. "Essai sur la vie et les ouvrages de Nicole Oresme". Paris: 1857.

MENJOT. "La politique monétaire de Nicolas Oresme". In: Souffrin, Segonds (eds.), 1988, pp. 179-193.

MORRISON, K. F. “Oresme's Livre de Politiques and the France Charles V by Susan M. Babbit". The American Historical Review, Vol. 91, Nr. 3, pp. 643-644, Jun. 1986.

NEVEUX. Nicole "Oresme et le clergé normand du XIV siècle". In: Quillet, 1990, pp. 9-36.

ORESME, N. "The De moneta of Nicholas Oresme and English Mint Documents". Ed. and transl. by Johnson. London: Thomas Nelson, 1956.

ORESME, N. "Traictie de la première invention des monnoies de Nicole Oresme". Ed. et trad. par Wolowski. Paris, 1864.

ORESME, N. "Nicole Oresme and the Medieval Geometry of Qualities and Motions: A Treatise on the Uniformity and Difformity of Intensities Known as "Tractatus de configurationibus qualitatum et motuu'". Ed. and transl. by M. Clagett. Madison: University of Wisconsin, 1968.

ORESME, N. "Le livre de Politiques d'Aristote". Ed. and transl. by Menut. Transactions of the American Philosophical Society, Philadelphia, Vol. 60, Nr. 6, 1970.

ORESME, N. "Le livre de Éthicques d'Aristote". Ed. et trad. par Menut. New York: G. E. Stechert, 1940.

OLIVI, P. "Un trattato di economia politica francescana: il De emptionibus et venditionibus, de usuris, de restitutionibus di Pietro di Giovanni Olivi". Ed. Todeschini. Rome: Istituto storico italiano per il medio evo, Studi Storici, 1980.

PASNAU, R. "Medieval Social Epistemology: Scientia for Mere Mortal". Episteme, Vol. 7, pp. 23-41, 2010.

QUILLET. “Autour de Nicole Oresme: Actes du Colloque Oresme”. Paris: J. Vrin, 1990. 
SOUFFRIN; SEGONDS (eds.). "Nicolas Oresme, tradition et innovation chez un intellectuel du XIVe siècle". Paris: Belles Lettres, 1988.

TAYLOR, C. C. W. "Nicomachean ethics books II-IV". Oxford: Oxford University Press, 2006.

ZINGANO, M. "Ethica Nicomachea I 13 - III 8. Tratado da virtude moral". São Paulo: Ed. Odysseus. 2008. 